\title{
Estimation of Transient over Voltages in Gas Insulated busduct from 220kv Gas Insulated Substation
}

\author{
M. Kondalu \\ Head \& Prof. of EEE \\ Joginpally B.R. Engineering \\ College \\ Hyderabad
}

\author{
Gillella Sreekanth Reddy \\ Asst. Prof. of EEE \\ Joginpally B.R. Engineering \\ College \\ Hyderabad
}

\author{
Dr.P.S.Subramanyam \\ Head \& Prof. of EEE \\ Vignana Bharathi Institute of \\ Technology \\ Hyderabad
}

\begin{abstract}
The transient over voltages are generated in gas insulated substations (GIS) during switching operation of substations in the order of a few nanoseconds. These transients have traveling wave behavior and travel to external systems through discontinuities and interface such as enclosures, bushings, cable joints etc. Depending up on configuration of the GIS and the amplitude of the electric and magnetic fields could be of the order of a few tens of kilovolts per meter and a few hundreds of amps per meter respectively. These very fast transient over (VFTO) voltages create critical situations in protection circuit and control circuit and makes raise faults in cables, transformers and secondary circuits, which result in malfunctioning of the primary equipment. The suppression of VFTO is very important in GIS systems. In this paper, included estimation of transient voltages in the switching operations has been calculated due to transient field with respect to $220 \mathrm{kv}$ gas insulated substation during switching operation. The effect of Transient field have been analyzed and clearly demonstrated for substation by develop of suitable simulation model to estimate over transient voltages. The proposed approach successfully implemented in the platform of MATLAB software.
\end{abstract}

\section{Keywords}

Gas Insulated Substation (GIS), Transient over voltages, switching operations, line faults and Control circuitry.

\section{INTRODUCTION}

For high-voltage transmissions, gas-insulated switchgears (GISs) are extremely advantageous and have been highly developed. One of their merits is compactness, which is advantageous in underground installation of substations, in particular, as well as indoor installation. Also, since all the high-voltage sections are housed in grounded enclosures, the GIS is a safe and highly reliable system, free of environmental hazards.

Some of the problems need attention includes generation of over voltages during dis-connector operations, line to enclosure faults, etc. These over voltages stress the equipment in GIS and reduce the reliability of the switchgear equipment.

VFT can be divided into internal and external. Internal transient create overvoltage between conductor and enclosure which can cause stress on the internal insulation of the GIS. External VFT is travelling waves and propagation outside GIS. These include transient enclosure voltage (TEV) between encapsulation and earth, transient electromagnetic fields (TEMF) radiated from enclosure which can cause stress on the secondary equipments and overvoltage on adjacent equipments [4]. The maximum magnitude of the transient over voltage is 2.0 p.u. this value is largely dependent upon the level of trapped charge on the GIS bus bar existing at the time of the re-strike. The amplitude of trapped charge is strongly influenced by the asymmetry of the inter-contact break down voltage occurring on the fixed and mobbing contacts of the dis-connector.

Under certain system configurations, the isolator switching operations could result in energizing or de-energizing a short section of GIS duct. Because of the relatively slow movement of the contacts of the isolator switches, pre-strikes or restrikes would occur between the contacts, creating VFTO on the GIS [Reference 1 3], and introducing a risk on the connected equipment, especially for transformer connected circuit. Due to its high frequency nature, the VFTO imposed on the transformers connected directly to the GIS would not be distributed evenly on all transformer windings. Some windings, e.g. the first few turns connecting to the $400 \mathrm{kV}$ GIS, would be subject to a higher magnitude of overvoltage, posing a potential risk of insulation breakdown of the transformers.

Even though the transient field amplitudes, in general, decrease with an increase of distance from the high-voltage (HV) bus, it is very often seen that the electronic equipment are present in the vicinity of the HV equipment of the GIS. This has lead to concern for the compatibility of the electronic equipment with the interfering environment, in which they must operate satisfactorily. Each switching operation produces multiple transient fields, whose magnitude, number, and wave shape vary with the rated voltage of the substation, type/speed of the switch being operated, and electrical characteristics of the high-voltage bus. These electromagnetic (EM) fields contribute to significant radiated fields and couple energy to the control equipment [3].

In this paper, induced voltages have been calculated on the control cables with both-end/one-end grounding of the cable sheath. In the first phase of the study, induced voltages have been calculated in the control circuitry for the entire frequency range, by assuming fixed transient field levels. This exercise will be helpful to understand the effect of frequency content of the transient fields on the induced voltages in the control circuitry. The influence of type of the control circuit and LC loading of the same on the voltage levels has been analyzed. Finally, the induced voltages are calculated at the load circuit of the control cables/wiring due to the transient field emission from the GIS modules. The dominant frequency components of these voltages have also been reported.

\section{MODELLING OF 220KV BUS SYSTEM}

During the current operation dis-connector switching a GIS is strikes (Pre-Strikes) occur because of the low speed of the des-connector switch moving contact, due to the very fast voltage collapse within a few nano seconds(ns) and the 
subsequent traveling waves very fast transient over voltages are developed. The main ossification of the fast transients depends on the configuration of GIS. Moreover, the effect of complexity of the configuration of GIS on the peak value of the transients has described in previously.

For the development of equivalent circuit low voltage step response measurements of the mail GIS components have been made. Using MATLAB of the equivalent models are developed. The peak value of fast transients often occurs when circuit structure is relatively simple, more frequently if the structure is rather complicated. The propagation velocity of traveling wave generated during dis-connector switch operation is about $30 \mathrm{~cm} / \mathrm{ns}$
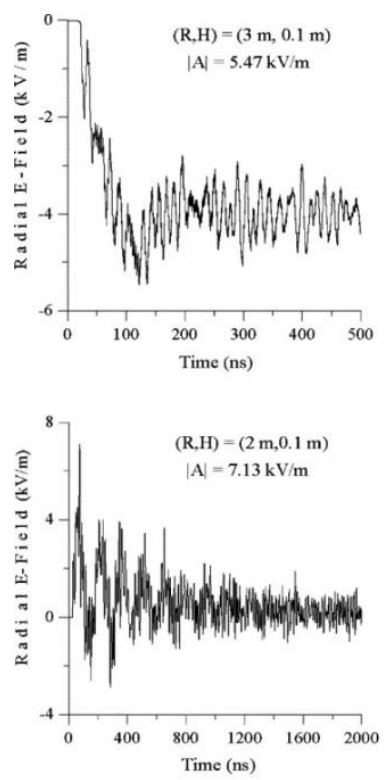

(a)
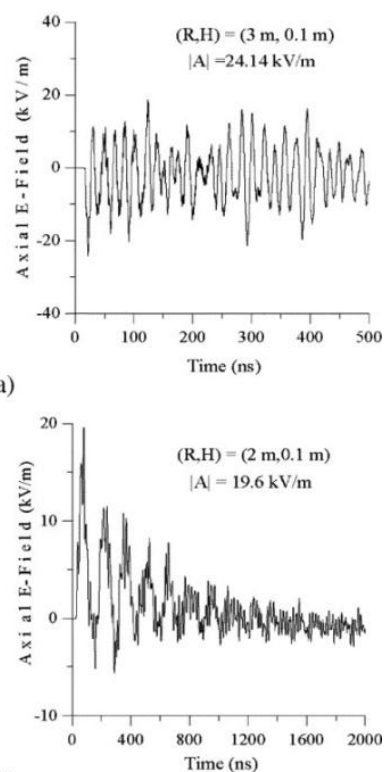

(b)

Fig. 1. Transient fields generated during switching. (a) Bus section. (b) Gas-to-air brushing.

Fig. 1 shows the transient fields leaking out from the gasinsulated bus duct and the gas-to-air bushing modules during switching operations. From the figure, it is seen that the radial and axial E-field levels computed for the bus section model, at a radial distance $(\mathrm{R})$ of $3 \mathrm{~m}$, axially located at the middle of the bus section and just above the ground plane.

\subsection{Capacitance calculation}

The Capacitance is calculated with the assumption that the conductors are Cylindrical. Capacitance is calculated by using the standard formulae given below.

$$
C=\frac{2 \pi \varepsilon_{0} \varepsilon_{r} l}{2.3 \times \ln \left(\frac{b}{a}\right)}
$$

Where $\varepsilon_{0}=8.854 \times 10^{-12}, \varepsilon_{r}=1$

$$
\begin{aligned}
& \mathrm{b}=\text { Outer cylinder radius } \\
& \mathrm{a}=\text { Inner cylinder radius } \\
& \mathrm{l}=\text { Length of the section }
\end{aligned}
$$

\subsection{Spacers capacitance}

The spacer existed with finite thickness and develops some amount of capacitance in addition with existed capacitance. Spacers are used for supporting the inner conductor with reference to the outer enclosure. They are made with Alumina filled epoxy material whose relative permittivity (er) is 4 . The thickness of the spacer is assumed to be the length of the capacitance for calculation.

\subsection{Inductance calculation}

The inductance of the bus duct can be calculated by using the formula [8] given below, where $r 1, r 2, r 3, r 4$, are the radii of the conductors in the order of decreasing magnitude and ' 1 ' is the length of the section.

$$
L=0.001 \times l \times\left(\begin{array}{c}
\ln \left(\frac{r 1}{r 3}\right)+\ln \left(\frac{r 2}{r 1}\right)+\ln \left(\frac{r 4}{r 3}\right)+ \\
2 \times \frac{\left(\frac{r 2}{21}\right)^{2}}{1-\left(\frac{r 2}{r 1}\right)^{2}} \times \ln \left(\frac{r 1}{r 2}-1\right)
\end{array}\right)
$$

\subsection{Calculation of variable arc resistance}

Based on the fundamentals of Circuit Breaker a specially in SF6 gas circuit breaker, Toepler's Spark Law is valid for calculation of Variable Arc Resistance. The Variable Arc Resistance due to Toepler's formulae [7] is given below:

$$
R=\frac{K_{T} \times l}{q_{0}+\int_{0}^{t} i(t) d t}
$$

Where $\mathrm{K}_{\mathrm{T}}$ = toepler's constant

$=0.005$ volt.sec/mt for SF6 under uniform field conditions

$\mathrm{L}=$ spark length in meters

$\mathrm{Q} 0=$ Initial charge or charge at the instant of breakdown

$\mathrm{T}=$ spark collapse time in sec 


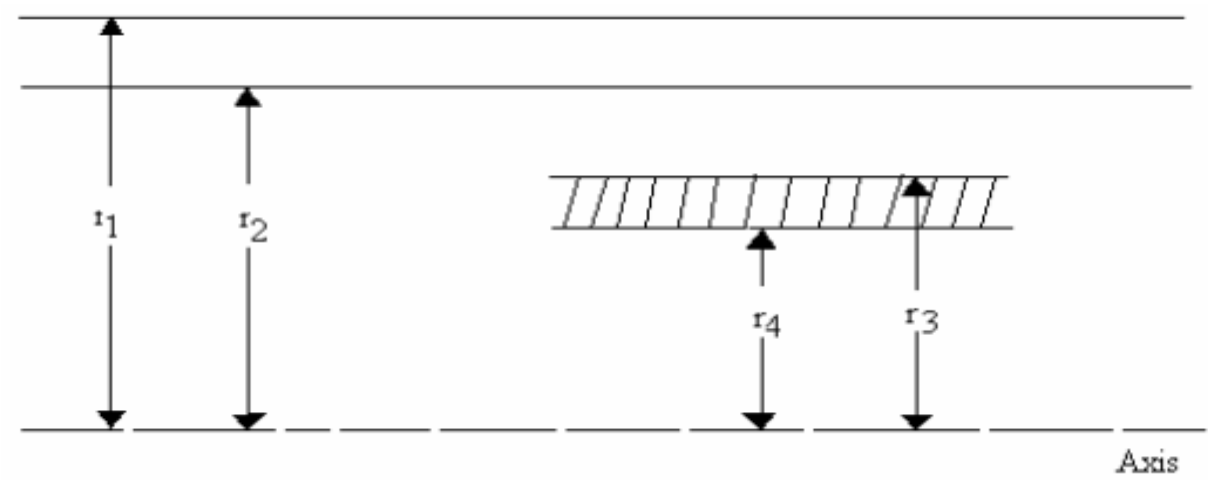

Fig 2. Cross Section of typical GIS system

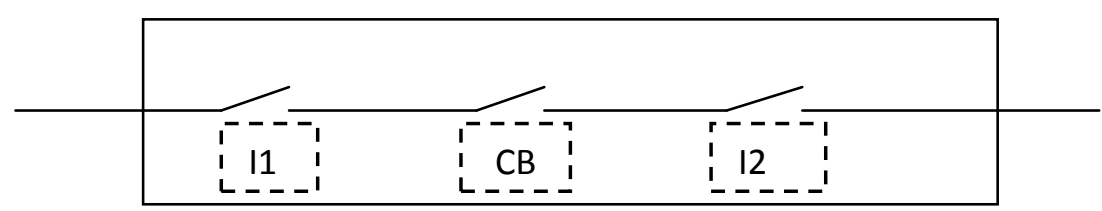

Fig. 3 Electric circuit to explain the arc phenomenon

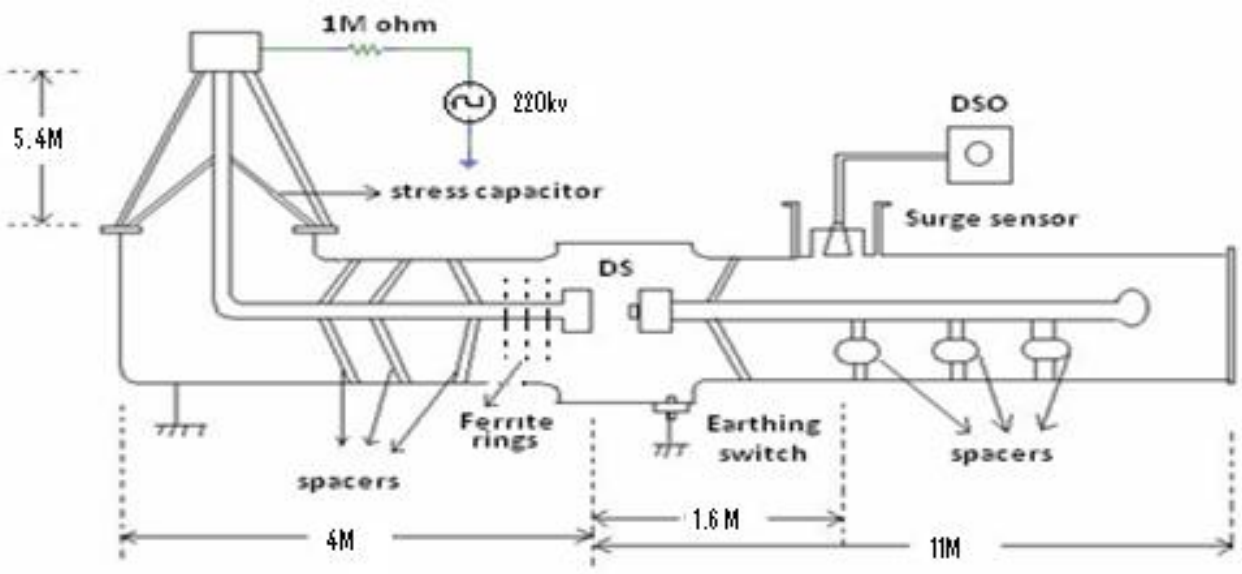

Fig. 4 Modeling diagram of 220kv GIS System

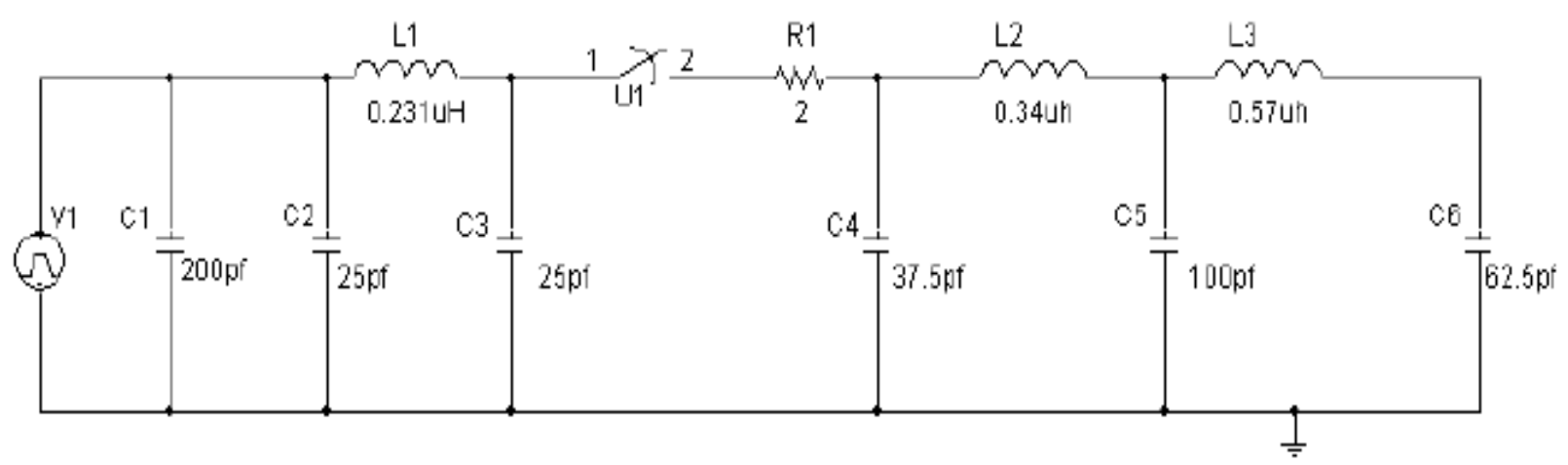

Fig. 5 single phase equivalent circuit for $5 \mathrm{mts}$ length GIS 
The value of time varying spark resistance $R(t)$ is calculated until it reaches a value of 1 to $3 \mathrm{ohms}$. The integral in the denominator sums up the absolute value of current ' $i$ ' through the resistance $\mathrm{R}(\mathrm{t})$ over the time beginning at breakdown inception. Thus, it corresponds to the charge conducted through the spark channel up to time ' $t$ '.

The modeling diagram of $220 \mathrm{kv}$ GIS system as in the fig.,4 and the following arrangement is assumed for the developing the model and the are phenomena and gas insulated substation concepts can analysis by fig. 3 and fig 4 .

The apparatus as disconnected with an earthing switch, four disc type Spencer's, a load bus bar above to $10 \mathrm{mts}$ long width three post type spencers and a $220 \mathrm{kv}$ gas bushing containing stress capacitor.

The $1 \mathrm{GHZ}$ surge sensor method in the diagram is located at the distance of $1.6 \mathrm{mts}$ from disconnector further, holding the lad side bus bar at zero potential, dc voltage was applied from the high voltage dc power supply to the bushing via a $1 \mathrm{Mohm}$ resistor and VFTO wave of the closing operations was observed.

\section{SINGLE PHASE EQUIVALENT CIRCUIT FOR 220K GIS SYSTEM FOR 5MTS LENGTH}

The bus duct is dividing into three sections of length from load side. The GIS bushing is represented by a capacitance of 200pf. The resistance of $2 \mathrm{ohm}$ spark channel is connected in series with circuit breaker. The equivalent circuit shown in below fig. 5 .

Due to trapped charge some voltage remains on the floating section which can create severe conditions because the first re-strike can occur at the peak of power frequency voltage giving a voltage of $2.0 \mathrm{pu}$. On re-strike the voltage on each side will collapse initially zero and hence creating two $1.0 \mathrm{pu}$ voltage steps of opposite polarities. In this, it is assumed that re-striking is created at $1.0 \mathrm{pu}$. Respectively on either side of dis-connector switch (DS). The transients due to closing of the circuit breaker are calculated and maximum voltage obtained with a rise time.

The proposed method implemented on MATLAB 7.6. the voltage before and after circuit breaker is taken to be $1.0 \mathrm{pu}$ and $-1.0 \mathrm{pu}$ as the most enormous condition but depending on the time of closing of circuit breaker the magnitude of the voltage on the load side changes.

The following two switching operations are considered in the present study.

1) Closing operation of disconnector switch, when circuit breaker is open.

2) Closing operation of circuit breaker.

For different values of voltages on the load side the magnitudes and rise time of the voltage wave are calculated keeping source side voltages as constant as 1.0pu. the values are tabulated in table I.

Similarly by changing the magnitudes of the voltage on the source side, keeping voltage on load side constant at 1.0p.u. then the transient due to variation of voltage on source side obtained. The values are tabulated in Table II
Table I Transient due to variation of voltage on lode side

\begin{tabular}{|c|c|c|c|}
\hline $\begin{array}{l}\text { S.n } \\
\text { o }\end{array}$ & $\begin{array}{c}\text { Load side } \\
\text { Voltage } \\
\text { (p.u) }\end{array}$ & $\begin{array}{c}\text { Magnitude of } \\
\text { the voltage } \\
\text { (p.u) }\end{array}$ & $\begin{array}{c}\text { Rise } \\
\text { Time } \\
\text { (nanos) }\end{array}$ \\
\hline 1 & -1.0 & 2.45 & 9 \\
\hline 2 & -0.9 & 2.33 & 12 \\
\hline 3 & -0.8 & 2.17 & 9 \\
\hline 4 & -0.7 & 2.14 & 10 \\
\hline 5 & -0.6 & 1.96 & 12 \\
\hline 6 & -0.5 & 1.85 & 10 \\
\hline 7 & -0.4 & 1.70 & 12 \\
\hline 8 & -0.3 & 1.60 & 12 \\
\hline 9 & -0.2 & 1.45 & 12 \\
\hline 10 & -0.1 & 1.37 & 10 \\
\hline
\end{tabular}

Table II Transients due to variation of voltage on source side

\begin{tabular}{|c|c|c|c|}
\hline S.no & $\begin{array}{c}\text { Source side } \\
\text { Voltage } \\
\text { (p.u) }\end{array}$ & $\begin{array}{c}\text { Magnitude of } \\
\text { the voltage } \\
\text { (p.u) }\end{array}$ & $\begin{array}{c}\text { Rise Time } \\
\text { (nanos) }\end{array}$ \\
\hline 1 & 1.0 & 2.45 & 9 \\
\hline 2 & 0.9 & 2.38 & 11 \\
\hline 3 & 0.8 & 2.26 & 11 \\
\hline 4 & 0.7 & 2.09 & 12 \\
\hline 5 & 0.6 & 2.02 & 11 \\
\hline 6 & 0.5 & 1.84 & 12 \\
\hline 7 & 0.4 & 1.73 & 10 \\
\hline 8 & 0.3 & 1.63 & 11 \\
\hline 9 & 0.2 & 1.50 & 10 \\
\hline 10 & 0.1 & 1.38 & 10 \\
\hline
\end{tabular}

\section{RESULTS AND DISCUSSION}

The different transient voltage and current at different positions ina $220 \mathrm{kv}$ GIS for the first switching operation presented in results. The highest magnitude of transient current occurs near the disconnector switch. This is contrast to the peak magnitude for fast transient over voltages, which occurs at open ends. The peak magnitude of transient current observed to decrease with distance from the switch and at cable end it is about $4.12 \mathrm{ka}$. to understand the effect of switching configuration on peak magnitude os transient currents at different positions, fast transient currents have been estimated for the second switching configuration as shown in below figs.

Assumed that there is a second re-strike another switch is connected in parallel to the circuit breaker for simulation in matlab modeling. Transients are calculated by closing this switch when voltage difference across the contacts of the circuit breaker reaches maximum value.

During closed operation, the current through the resistance of the circuit breaker is shown in fig.6 and fig.7. From the graph it was found the maximum current is $30 \mathrm{~A}$ at a rise time of 12 ns. 


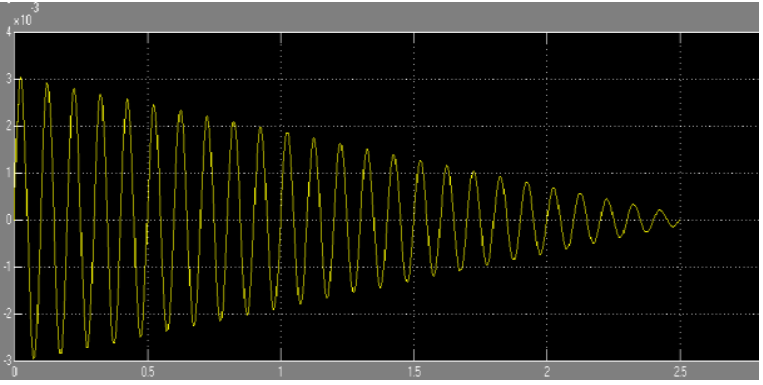

Fig. 6 Current waveform during closing operation of $\mathrm{CB}$ for $5 \mathrm{mts}$ GIS

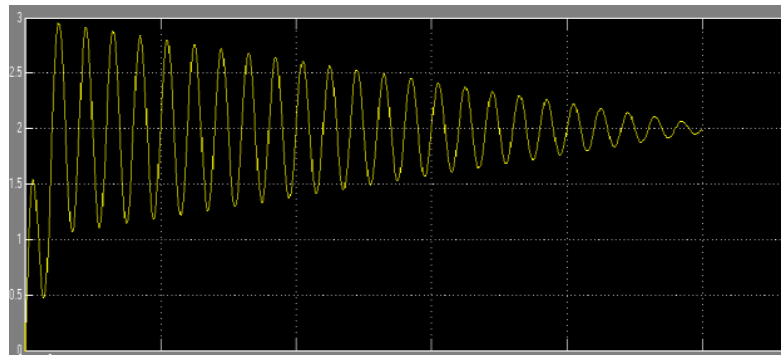

Fig 7 transient voltage wave from during closing operation of CB for $5 \mathrm{mts}$ GIS

To introduce current chopping, the circuit breaker is opened. Hence to calculate transients due to opening operation the $\mathrm{CB}$ is opened at 10ns. The transients are obtained and show in fig 8.

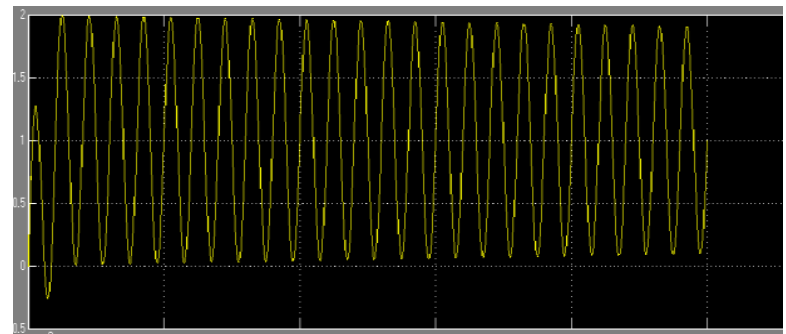

Fig. 8 transient voltage waveform during opening operation of CB for 5mts GIS

The transient calculated due to second re-strike gives the peak voltage of $2.22 \mathrm{p}$.u at a rise time of $16 \mathrm{~ns}$ show in fig. 9

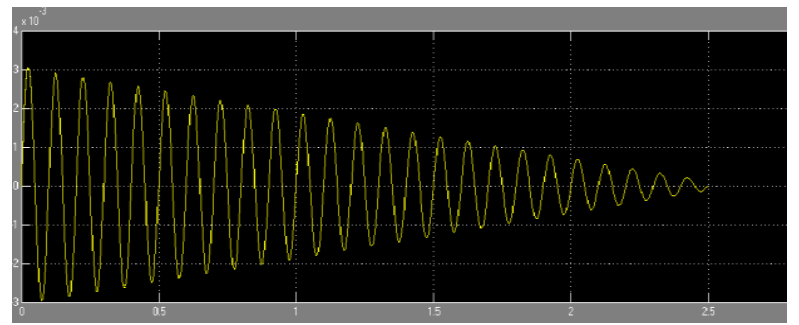

Fig.9 transient voltage waveform during second re-strikes for $5 \mathrm{mts}$ GIS
The values are tabulated as follows:

\begin{tabular}{|c|c|c|}
\hline $\begin{array}{c}\text { Mode of } \\
\text { operation }\end{array}$ & $\begin{array}{c}\text { Magnitude of } \\
\text { voltage(p.u) }\end{array}$ & $\begin{array}{c}\text { Rise time } \\
\text { (nano sec) }\end{array}$ \\
\hline $\begin{array}{c}\text { During closing } \\
\text { operation }\end{array}$ & 3.02 & 30 \\
\hline $\begin{array}{c}\text { During } \\
\text { opening } \\
\text { operation }\end{array}$ & 2.01 & 18 \\
\hline $\begin{array}{c}\text { During second } \\
\text { re-strike }\end{array}$ & 2.22 & 16 \\
\hline
\end{tabular}

\section{CONCLUSION}

The peak magnitude of fast transient currents generated during switching event changes from one position to another in a $220 \mathrm{kv}$ GIS for a particular switching operation. These transients over voltages are reduced by connecting suitable resistor in an equivalent circuit during closing and opening operation.

The maximum possible amplitude of transient current for the above two switching operations is in the range of $4 \mathrm{kA}$. The peak magnitude of transient current at cable end depends on switching configuration

\section{REFERENCE}

[1] L. G. Christophorou, J. K. Olthoff, R. J. Van Brunt, "SF6 and the Electric Power Industry", IEEE Electrical Insulation Magazine, DEIS, 1997, pp. 20-24.

[2] G.V.Nagesh Kumar J.Amarnath, B.P.Singh, K.D.Srivatsava., "Influence of Power frequency and Impulse voltages on particle movement in Gas Insulated Bus duct (GIB) with epoxy coatings". at National Seminar on Insulating materials for the Power Industry, organized by Central Power Research Institute, Bangalore during 26-27 August, 2004

[3] G.V.Nagesh Kumar, J.Amarnath, B.P.Singh, K.D.Srivatsava "Particle movement in a $245 \mathrm{KV}, 300$ $\mathrm{KV}$ and $400 \mathrm{KV}$ Gas Insulated Substations with and without dielectric coating enclosure" National Conference APSC 2004 NIT, Rourkela

[4] Boggs SA., Chu F.Y. and Pujimotor N. (IYXZ), 'Disconnect Switch Induced Transients and Trapped Charge in GIs', EEE Trans. PAS, Vol. PAS-101, No. IO, pp 3593-3601.

[5] Mohana Rao M., Naidu M.S. (199\% 'Estimation of Fast Transient Overvoltages in the case of Disconnnector operation in a GIS', 3d workshop \& conference on EHV Technology, IISC Bangalore.

[6] J.B. Kim,M.S. Kim,K.S.Park, W.P.Son.,.D.S. Kim, G.S. Kil. Development of monitoring and diagnostic system for SF6 gas insulated switchgear. IEEE Conference Record of the 2002 IEEE International Symposium on Electrical Insulation. Boston, Massachusetts, UnitedStates, pp.453-456,2002. 